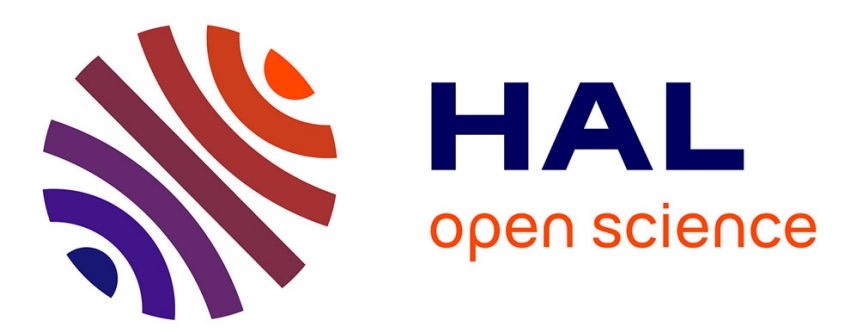

\title{
Formation Process of Lamella Structures by Deformation in an Fe-Mn-Si-Cr-Ni Shape Memory Alloy
}

\author{
T. Kikuchi, S. Kajiwara, Y. Tomota
}

\section{To cite this version:}

T. Kikuchi, S. Kajiwara, Y. Tomota. Formation Process of Lamella Structures by Deformation in an Fe-Mn-Si-Cr-Ni Shape Memory Alloy. Journal de Physique IV Proceedings, 1995, 05 (C8), pp.C8445-C8-450. 10.1051/.jp4:1995867 . jpa-00254116

\section{HAL Id: jpa-00254116 https://hal.science/jpa-00254116}

Submitted on 1 Jan 1995

HAL is a multi-disciplinary open access archive for the deposit and dissemination of scientific research documents, whether they are published or not. The documents may come from teaching and research institutions in France or abroad, or from public or private research centers.
L'archive ouverte pluridisciplinaire HAL, est destinée au dépôt et à la diffusion de documents scientifiques de niveau recherche, publiés ou non, émanant des établissements d'enseignement et de recherche français ou étrangers, des laboratoires publics ou privés. 


\title{
Formation Process of Lamella Structures by Deformation in an Fe-Mn-Si-Cr-Ni Shape Memory Alloy
}

\author{
T. Kikuchi*,(1), S. Kajiwara* and Y. Tomota** \\ * National Research Institute for Metals, 1-2-1 Sengen, Tsukuba, Ibaraki 305, Japan \\ ** Department of Materials Science, Faculty of Engineering, Ibaraki University, Hitachi, Ibaraki 316, \\ Japan
}

\begin{abstract}
For Fe-Mn-Si-Cr-Ni shape memory alloys, it was previously found by HREM study that the formation of the nanometric lamella structures consisting of f.c.c. and h.c.p. phase is very important to exhibit good shape memory effect. In the present work, the formation process of such lamella structures has been studied in detail. The results are as follows. The transformation is initiated by random formation of extremely thin martensite plates with 1-2 nm width and then these plates are clustered and some of them coalesce to form thicker martensite plates with increasing deformation. The clustered regions are $400-600 \mathrm{~nm}$ wide and will correspond to the above mentioned lamella structures. These clustered regions are considered also to correspond to the thinnest martensite plate observable with optical microscope. In the optical microscopic scale, the thin martenite plates with the smallest width are formed rather uniformly in an austenite grain, and with further increasing deformation, they are clustered and coalesce into thicker plates with 3-8 $\mu \mathrm{m}$ width.
\end{abstract}

\section{INTRODUCTION}

In the past decade, Fe-based shape memory alloys have drawn much attention because the costs of production are very low. These are Fe-Mn-Si [1-9], Fe-Mn-Si-Cr-Ni [10-16], Fe-Ni-Co-Ti [17-20] and Fe-Ni-C $[21,22]$. The martensitic transformations involved in these memory alloys are the f.c.c./h.c.p. transformation for the first two cases and the f.c.c./b.c. t. transformation for the latter two cases. Among these alloys, the most promising alloy will be the Fe-Mn-Si-Cr-Ni alloy which is a modification of Fe$\mathrm{Mn}-\mathrm{Si}$ alloy and has a property of corrosion-resistance comparable to the stainless steels. However, in order to obtain a good shape memory effect (more than $80 \%$ shape recovery) for this alloy, some kinds of thermomechanical treatments are necessary. For the as-solution treated specimen, only about $50 \%$ shape recovery is obtained. One of the thermomechanical treatments is so-called the "training" $[9,11]$. The other is such that a specimen which has been solution-treated at $1320 \mathrm{~K}$ for $30 \mathrm{~min}$ is first cold-rolled by $10 \%$ at room temperature and then heated at $970 \mathrm{~K}$ for $10 \mathrm{~min}$.

Recently, in order to know the origin of the improved shape recovery in the thermomechanically treated specimen of this alloy, Ogawa and Kajiwara [23] studied in detail the deformation structures produced by $4 \%$ extension, using a high resolution electron microscope. In their experiment, specimens were subjected to the thermomechanical treatment of the latter type mentioned above. They found that the minimum unit of deformation band with about $0.2 \mu \mathrm{m}$ generated in the thermomechanically treated specimen consists of lamella structure having a mixture of h.c.p. and f.c.c. phase with 1-10 nm widths, but in the case of non-thermomechanically treated specimen, the deformation band mostly consists of h.c.p. phase only. They have attributed the observed good shape memory effect to the easiness of the reverse transformation (h.c.p. $\rightarrow$.f.c.c.) on heating, because there is no need for the nucleation of f.c.c. phase in the h.c.p. martensite, that is, extremely thin plates of f.c.c. phase in the lamella structure serve as starting places for the reverse transformation by thickening.

From the work of Ogawa and Kajiwara mentioned above, it seems that the formation of nanometric lamella structures which consist of parent phase (f.c.c.) and martensite (h.c.p.) is essential for this alloy to exhibit good shape memory effect. It is then very important to know the formation process of such lamella structures. The aim of the present work is to clarify various steps of the stress-induced martensite plate formation in this alloy, by using optical and electron microscoopes.

\section{EXPERIMENTAL METHOD}

The alloy used is an $\mathrm{Fe}-14 \mathrm{Mn}-6 \mathrm{Si}-9 \mathrm{Cr}-5 \mathrm{Ni}$ (mass\%) alloy. The specimens were subjected to the thermomechanical treatment of the latter type mentioned above. By this treatment, the shape recovery for $4 \%$ extension is increased to $80 \%$ from $50 \%$ of the non-thermomechanically treated specimen.

${ }^{(1)}$ T. Kikuchi is studying also in the special Course of the graduate school of Ibaraki University 
The specimen thickness was $0.4 \mathrm{~mm}$ in the cold-rolled state. The change in surface relief due to the stress-induced martensite transformation during extension was continuously observed by differential optical microscope. For electron microscopic observation, specimens were thinned by the twin-jet polishing technique after extension of $0.2,0.8,1.6,3.0$ and $4.0 \%$, respectively.

\section{RESULTS and DISCUSSION}

\subsection{Optical microscopic observation}

Figures 1 (a)-(d) show a series of optical micrographs which were taken during extension at a constant strain rate of $1.1 \times 10^{-4} / \mathrm{s}$. Double arrow indicates the point serving as a fiducial marker. The tensile axis is parallel to the horizontal direction of these micrographs. The continuous observation of the surface relief was made by differential optical microscope, using a CCD camera. The corresponding stress-strain curve is shown in Fig. 2, in which arrows (a), (b) (c) and (d) indicate the points where micrographs (a)(d) in Fig. 1 were taken. Stress levels at these points were 79, 183, 242 and $316 \mathrm{MPa}$ for (a), (b), (c) and (d), respectively. It should be noted that martensite plates with about $1 \mu \mathrm{m}$ are formed even below the yield point indicated by upward double arrow in Fig. 2. The numbers of martensite plates in the observed area in (a)-(d) in Fig. 1 are 12, 20, 25, and 26, respectively. We notice that the number of newly nucleated martensite plates is much larger in (a) to (b) than (b) to (c), or (c) to (d); that is, on passing the yield point in the stress-strain curve, a larger number of martensite plates have nucleated. However, there is no sharp yield point in the stress-strain curve as seen from Fig. 2.

As seen in Fig. 1, the width of each martensite plate seems to increase with increasing applied stress. Using a video printer, we have measured the change in martensite width as a function of applied stress in detail. Three typical examples are shown in Fig. 3. It may be infered from this figure that the martensite plate width is almost linearly increased with increasing applied stress after the stress exceeds the yield point. ( As for plate $\mathrm{C}$, the curve consists of two linear lines. )

So far we have stated that a thin martensite plate nucleates and then thickens later by increasing stress, but it turns out that this is not the case as shown in the following. Figure 4 shows a high resolution differential optical micrograh revealing that a martensite plate which seems to a single plate in an ordinary magnification micrograph consists of very thin martensite plates. The width of the thinnest plate observed in Fig. 4 is measured to be about $0.2 \mu \mathrm{m}$. Figure 5 shows a series of micrographs taken consecutively by stepwise extensions. This figrure reveals how a seemingly thick martensite plate has been formed by extension, that is, the elementary process of "thickening " of martensite plate is not the lateral growth of the plate but the nucleation of a new martensite at the place very close to the existing plate and the coalescence into one plate at a later stage as seen at the places indicated by arrows in the micrographs.

\subsection{Electron microscope observation}

In order to examine further details of stress-induced martensite formation, electron microscopic observations were made on the specimens extended by $0.2,0.8,1.6,3.0$ and $4.0 \%$, respectively. Figure 6 shows electron micrographs of martensite formed by extension of $0.2 \%$; (a) bright field image, (b) dark field image taken with 10.0 spot of h.c.p. martensite. An electron diffraction pattern of the corresponding area is shown in (c), which consists of [011]f.c.c. zone axis and [01.0] h.c.p. zone axis. As can be seen from the diffraction pattern in (c), the habit plane, (111)f.c.c., is parallel to the incident electron beam. In this paper, only electron micrographs with such orientation are presented; otherwise, we can not measure the martensite plate widths and their distribution. There are very good one to one correspondence of martensite plates in (a) and (b) in Fig. 6. From these microgrphs, it is measured that thickness of the martensite plates is $1-2 \mathrm{~nm}$ for thinner plates and about $30-45 \mathrm{~nm}$ even for thick plates. The other characteristic feature is that the martensite plates are rather uniformly formed at this stage of deformation.

As the amount of extension is increased, there appears a tendency that thin martensite plates are clustered in a certain region with the width of $400-600 \mathrm{~nm}$. Figure 7 shows such an example, in which martensite plates were formed by $1.6 \%$ extension. Here thick martensite plates with the width of $60-130$ $\mathrm{nm}$ in dark contrast have appeared, but it is evident from the upper left side area of the micrograph that these thick martensite plates consist of much thinner plates with the width of $3-10 \mathrm{~nm}$. It is noted in this figure that most of martensite plates are clustered within the central region with about $600 \mathrm{~nm}$ width.

Figure 8 shows an extremely high magnification micrograph of two neighboring very thin martensite plates with about $100 \mathrm{~nm}$ width which appeared in the specimen extended by $3 \%$. Striations with sharp dark contrast in the martensite plate correspond to stacking faults in the h.c.p. phase. From the facts that the contrasts of the striations are very sharp despite of extremely high magnification of the micrograph and its diffraction contrast is rather uniform, each of the striations presumably corresponds to a single 

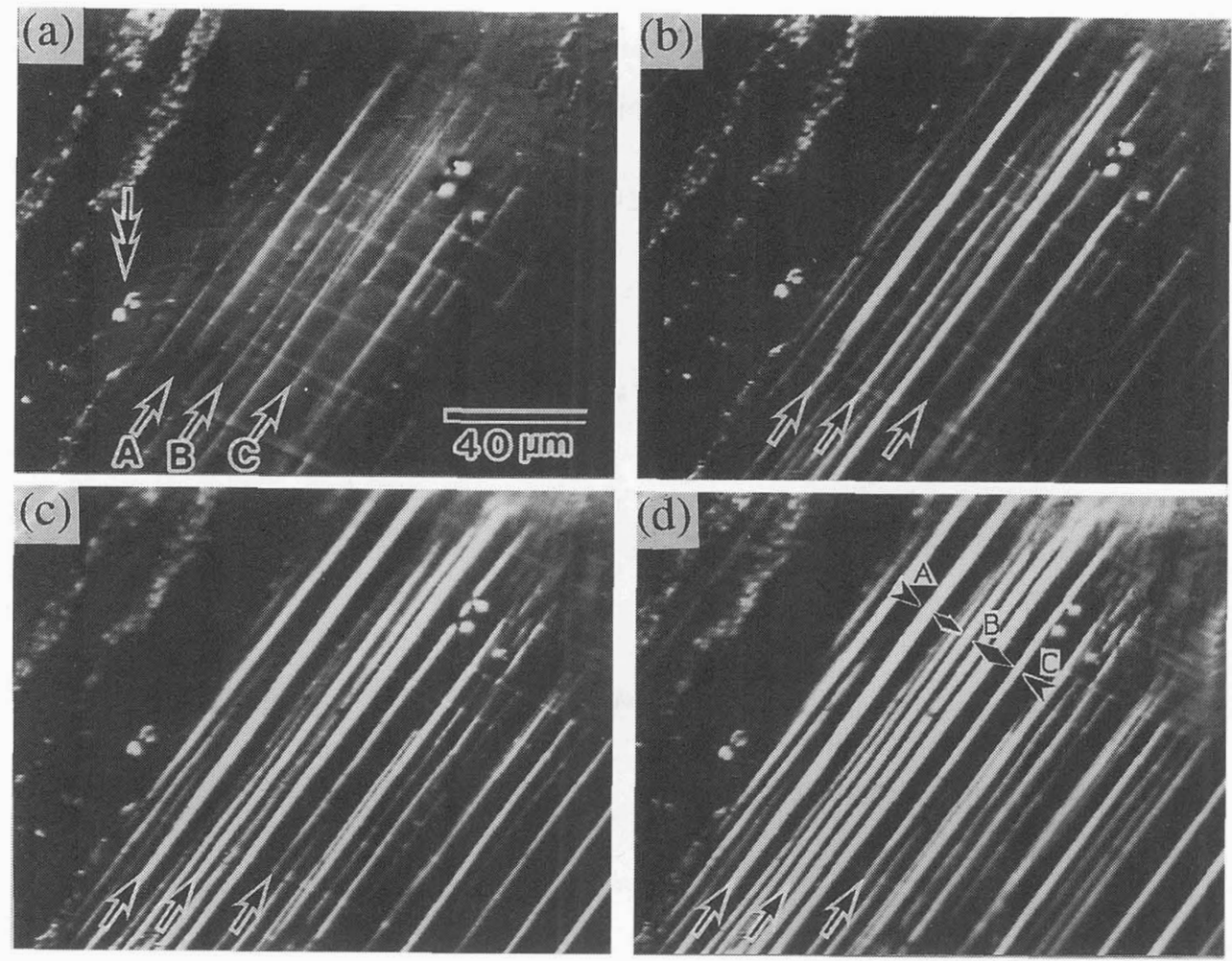

Fig. 1 Series of optical micrographs showing formation of h.c.p. martensite consecutively.

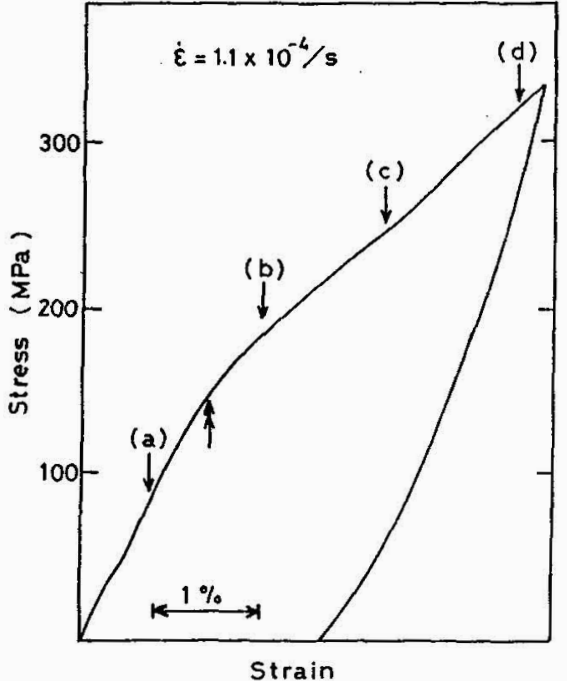

Fig. 2. Sress-strain curve when the specimen is stretched at $300 \mathrm{~K}$ at a strain rate of $1.1 \times 10^{-4} / \mathrm{s}$. Down arrows indicate the corresponding points where series of micrographs, (a)-(d), in Fig. 1 were taken.

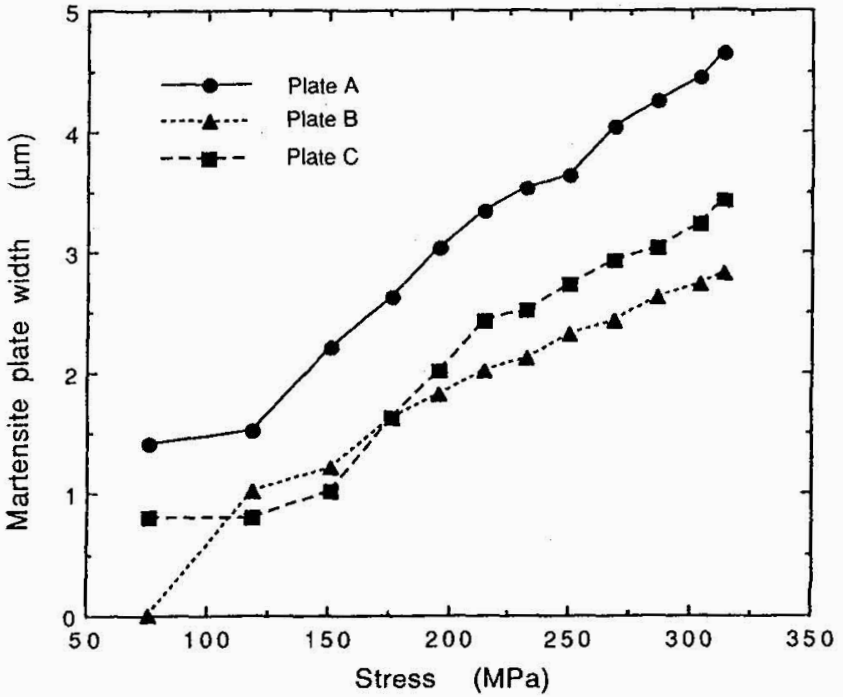

Fig. 3 Relation between width of martensite plate and applied stress for plates A, B and C in Fig. 1. The width increases almost linearly with stress. 


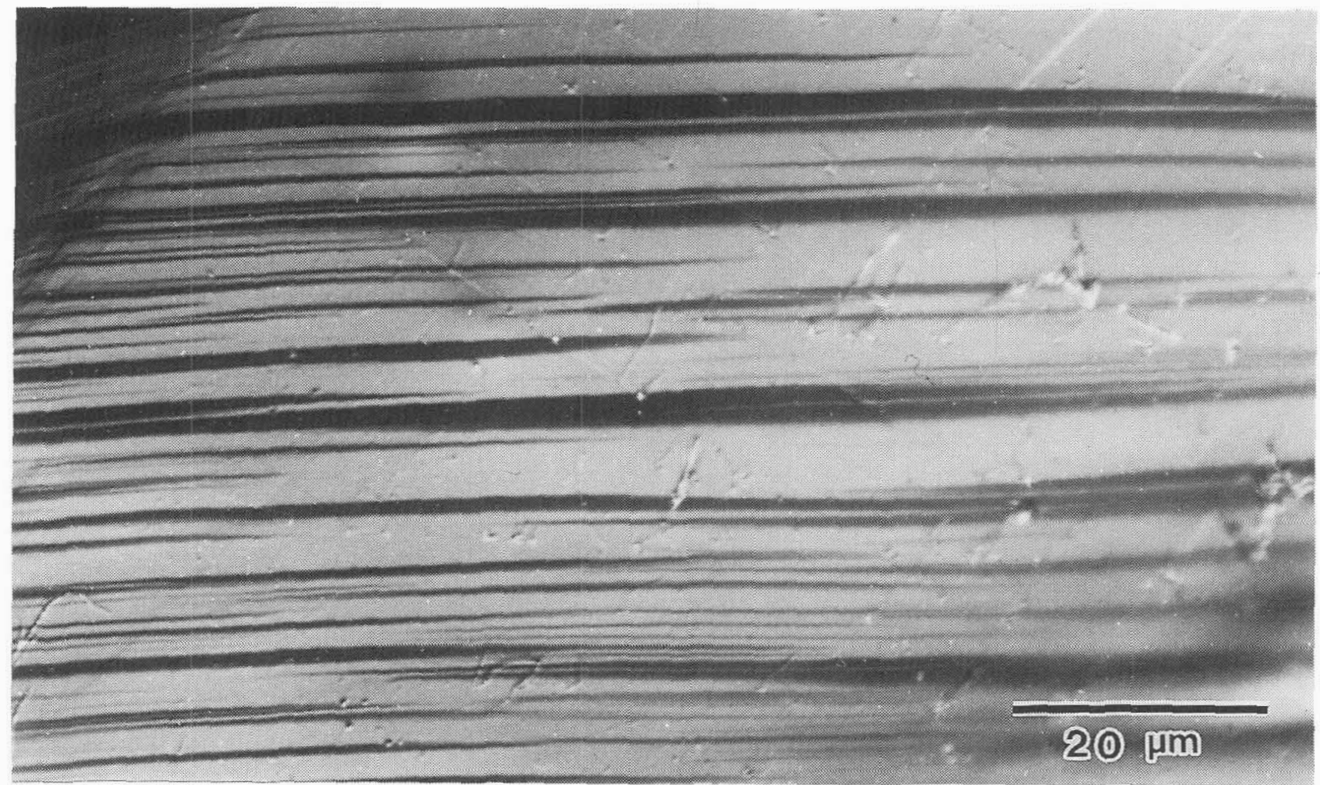

Fig. 4 High resolution differential optical micrograph, revealing very fine matensite plates.
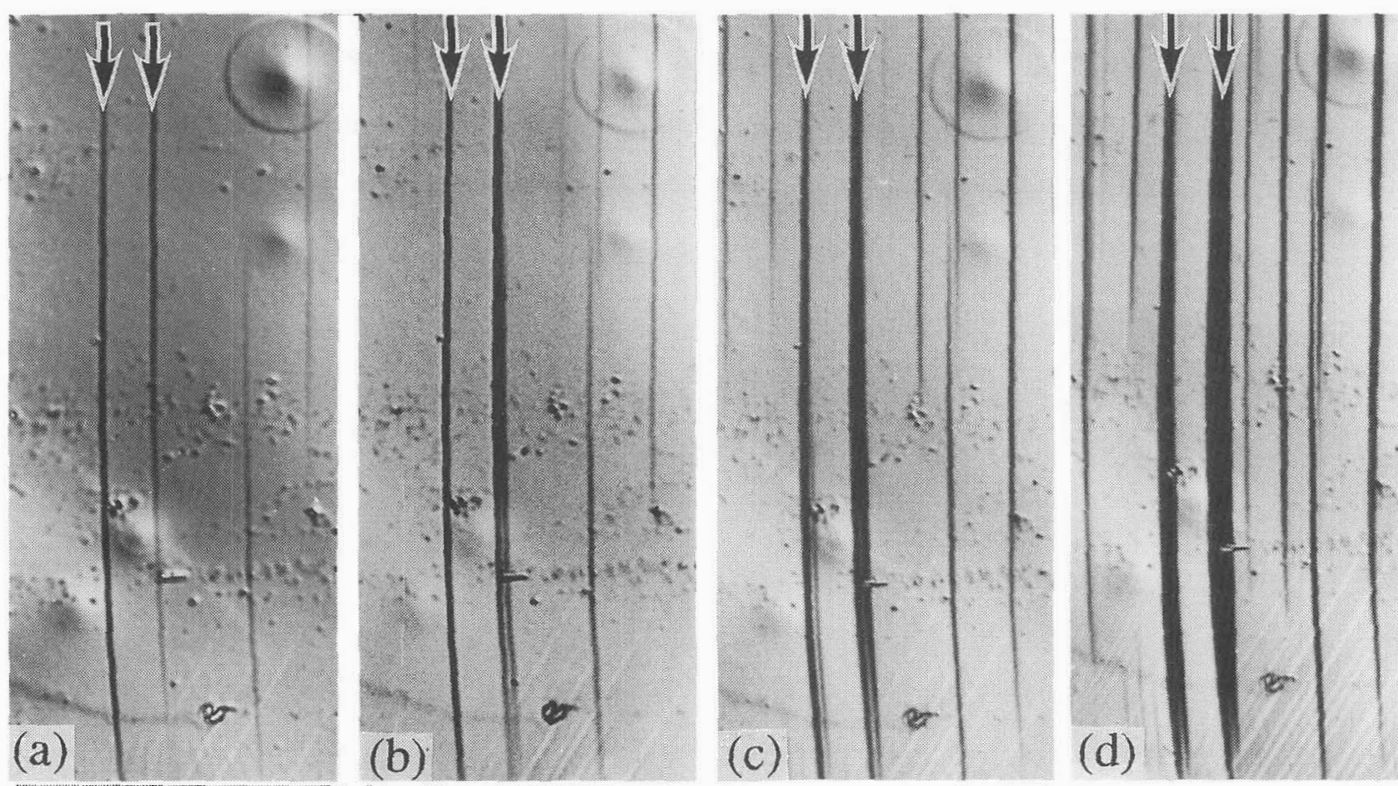

$50 \mu \mathrm{m}$

Fig. 5 . Series of differential optical micrographs taken consecutively by stepwise extension. 

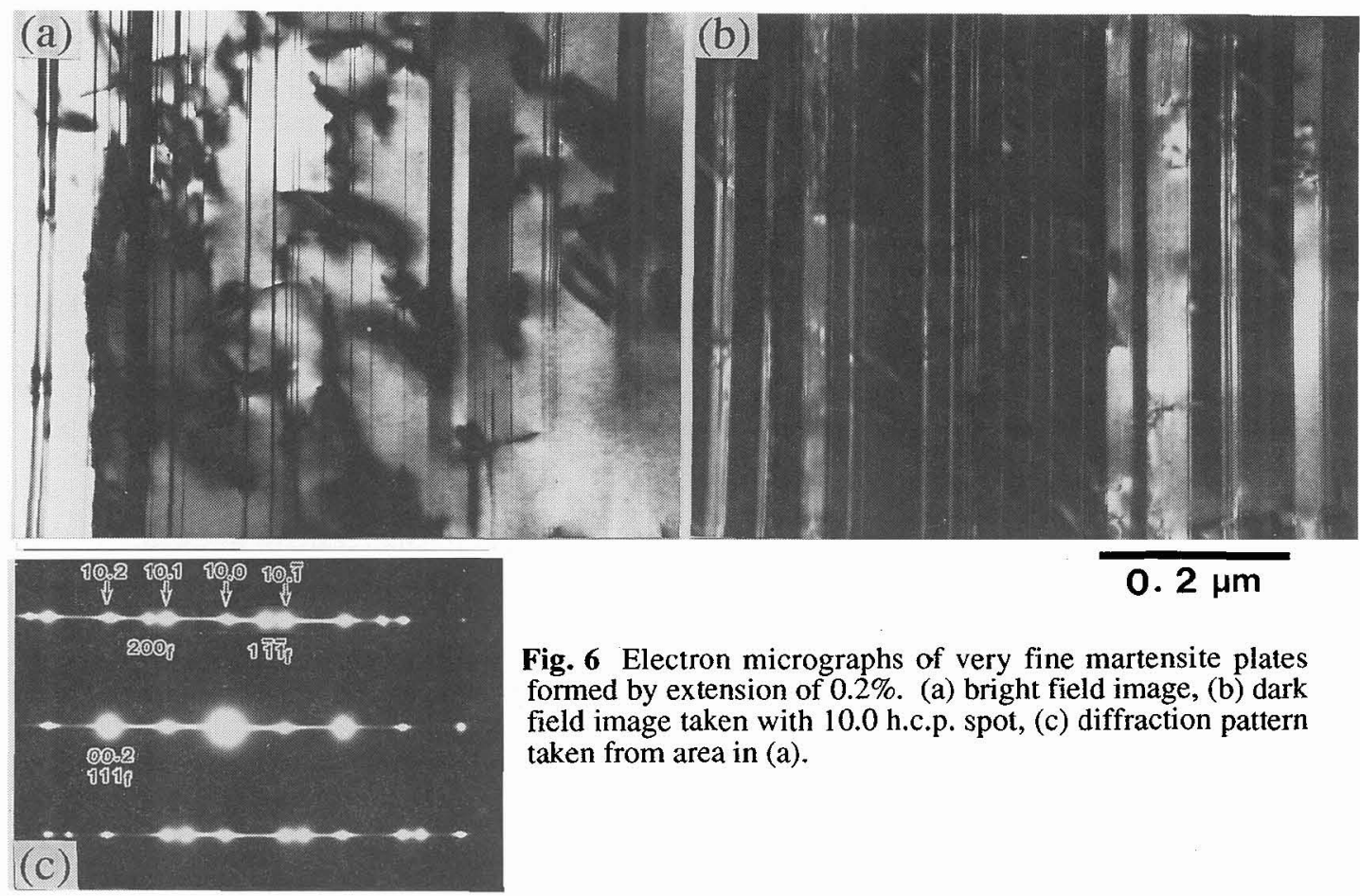

$0.2 \mu \mathrm{m}$

Fig. 6 Electron micrographs of very fine martensite plates formed by extension of $0.2 \%$. (a) bright field image, (b) dark field image taken with 10.0 h.c.p. spot, (c) diffraction pattern taken from area in (a).
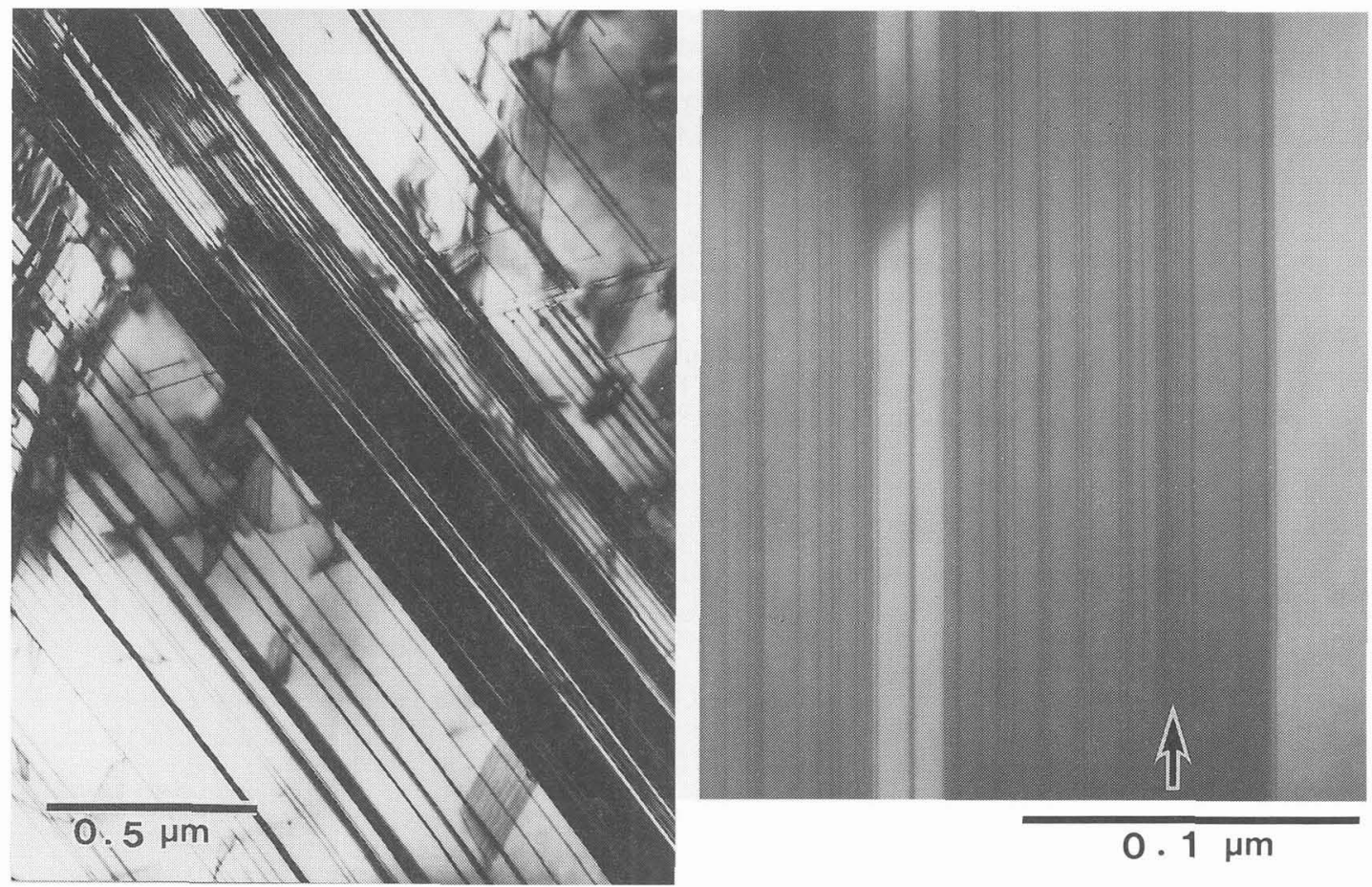

Fig. 7 Electron micrograph of martensite plates Fig. 8 High magnification electron micrograph formed by extension of $1.6 \%$. showing stacking faults in h.c.p. martensite. The fault plane is parallel to the incident beam. 
stacking fault lying on the $(00.1)$ h.c.p. plane which is parallel to the incident beam. We can then measure the spacing between the neighboring stacking faults. It turned out to be 0.8-1.4 nm in a dense region as indicated by arrow. If the average value is taken from the area shown in Fig. 8, it is 3-8 nm, which is comparable with those estimated from the analysis of electron diffraction patterns such as shown in Fig. 6 (c) [25].

From the experimental results described in the preceding sections, we can construct the formation sequence of stress-induced martensite as follows. In the earliest stage of deformation, very thin martensite plates with 1-2 nm width appear rather uniformly and then these plates coalesce to form a thicker martensite plate. In the next step, martensite plates are clustered in a certain region of 400-600 nm width, where several thick martensites are situated in the center and thinner martensite plates are distributed around them. This clustered region will correspond to the minimum unit of deformation band which consists of lamella structures of f.c.c. and h.c.p. phases reported in the previous work [23]. It should be noted here that the "thickness increase" does not mean the lateral growth of the martensite plate, instead, very thin plates nucleate close to existing martensite plate and coalesce with it in both the optical microscopic and electron microscopic scales. It is worth emphasizing that the coalescence is never complete and the f.c.c. phase is left between them as can be known by the previous work [23].

As mentioned above, the stress-induced transformation in the present alloy is basically accomplished by formation of groups of very thin martensite plates. This transformation mode will make it possible that the shape strain of martensite is accommodated elastically in the matrix (the parent phase). This nature greatly improves the shape memory effect, because 1) the plastic deformation in the parent phase can be avoided in principle at the time of martensite formation and 2), on heating, the strain field existing at the tip of a martensite plate will make easy the reverse motion of the Shockley partial dislocations which were associated with the formation of the h.c.p. phase.

\section{References}

[1] Sato A, Chishima E, Soma K. and Mori T., Acta Metall., 30 (1982) 1177.

[2] Sato A, Chishima E, Yamaji Y. and Mori T., Acta Metall., 32 (1984) 539.

[3] Sato A, Yamaji Y. and Mori T., Acta Metall., 34 (1986) 287.

[4] Murakami M, Otsuka H, Suzuki H. G. and Matsuda S., Proc. Int. Conf. on Martensitic Transformation, Nara, Japan, 1986 (The Japan Institute of Metals, 1987) p. 985.

[5] Sato A. and Mori T., Mater. Sci. Eng., A 146 (1991) 197.

[6] Hoshino Y, Nakamura S, Ishikawa N, Yamaji Y, Matsumoto S, Tanaka Y. and Sato A., Mater. Trans. $J I M, 33(1992), 253$.

[7] Tsuzaki K, Ikegami M, Tomota Y, Kurokawa Y, Nakagawara W. and Maki T., Mater. Trans. JIM , 33 (1992) 263.

[8] Tomota Y, Nakagawara W, Tsuzaki K. and Maki T., Scripta Metall., 26 (1992) 1571.

[9] Otsuka H, Murakami M. and Matsuda S., Proc. MRS Int. Meeting on Advanced Materials, Tokyo, 1988 (Materials Research Society 1989, vol. 9) p. 451.

[10] Otsuka H, Yamada H, Tanahashi H. and Maruyama T., Proc. Int. Conf. on Martensitic Transformation, Sydney, 1989 (Materials Science Forum vol. 56-58 (1990), Pt. II), p. 655.

[11] Otsuka H, Yamada H, Maruyama T, Tanahashi H, Matsuda S. and Murakami M., ISIJ International, 30 (1990) 674.

[12] Moriya Y, Kimura H, Ishizaki S, Hashizume S, Suzuki S, Suzuki H. and Sampei T., J. Physique IV (1991), C4-433.

[13] Ohtsuka H, Kajiwara S. and Ishihara T., Proc. In. Conf. on Martensitic Transformations, Monterey, California, 1992, (Monterey Institute for Advanced Studies, 1993), p. 1169.

[14] Fedrzoni L, Gex D, Gu Q, Guenin G, Labrosse D, Mantel M. and Vam Humbeeck J., ibid., p. 1175.

[15] Yang J. H . and Wayman C. M., ibid., p. 1193.

[16] Inagaki H., Z. Metallkd., 83 (1992) 90, 97, 304.

[17] Maki T, Kobayashi K,. and Tamura I., Proc. Int. Conf. on Martensitic Transformations, Leuven, Belgium, 1982,J. Physique C4, 43 (1982), p. 541.

[18] Maki T, Kobayashi K, Minato M. and Tamura I., Scripta Metall., 18 (1984) 1105.

[19] Maki T, Furutani S. and Tamura I., ISIJ International ,29 (1989) 438.

[20] Kikuchi T. and Kajiwara S., Mater. Trans. JIM, 34 (1993) 907.

[21] Kajiwara S., Trans. JIM, 26 (1985) 595.

[22] Kajiwara S. and Kikuchi T., Acta Metall., 83 (1990) 847.

[23] Ogawa K. and Kajiwara. S., Mater. Trans.JIM, 34 (1993) 1169.

[24] Kajiwara S., Japan. J. Appl. Phys., 4 (1970) 385.

[25] Kikuchi T, Kajiwara S. and Tomota Y., Mater. Trans. JIM, 36 (1995) 719. 